\title{
High Altitude Pulmonary Edema in a Healthy Pediatric Patient Traveling from Denver to Breckenridge
}

\author{
Matthew Adamo' \\ Kayla E Prokopakis' \\ Todd Bolotin ${ }^{1,2}$ \\ 'Department of Emergency Medicine, \\ Mercy Health St. Elizabeth Boardman \\ Hospital, Boardman, OH, USA; \\ ${ }^{2}$ Department of Emergency Medicine, \\ Centura Health St. Anthony \\ Breckenridge Mountain Clinic \\ Breckenridge, CO, USA
}

\begin{abstract}
A healthy 11-year-old boy presented with headache, nausea, and cough to a clinic at 2926 meters of altitude one day after ascending from his home altitude of 1578 meters. The patient had made multiple trips to the same altitude without any symptoms or sequelae throughout his childhood. Physical examination was significant for rales, tachycardia, and pulse oximetry level of $86 \%$ on room air. Radiographic evaluation with plain films revealed patchy alveolar opacities throughout the right lung. He received treatment with dexamethasone and high-flow face mask supplemental oxygen. In less than two hours, his rales had resolved, and his oxygen saturation had dramatically improved. He was discharged back to his native altitude and was at his baseline later the same day. High altitude pulmonary edema is a rare occurrence in children, but it is exceedingly rare for a healthy child with no history of pulmonary hypertension ascending only 1348 meters.
\end{abstract}

Keywords: high altitude pulmonary edema, HAPE, pediatrics, altitude

\section{Introduction}

Altitude illness can present in three different forms: Acute Mountain Sickness (AMS), High Altitude Pulmonary Edema (HAPE) and High Altitude Cerebral Edema (HACE). AMS, the most common of the three, can occur in $25 \%$ of individuals ascending from sea level to an elevation of 1920 to 2956 meters (m) in Colorado. ${ }^{1}$ Headache alone was found in $62 \%$ of visitors to $2987 \mathrm{~m}$ who came from below $914 \mathrm{~m}$ within 12 hours of arrival. ${ }^{1}$ The incidence of HAPE, a lifethreatening form of altitude illness, has been found to be much lower at $0.01 \%$ to $15.5 \%$, dependent upon the maximum altitude attained. ${ }^{2}$ It is defined as noncardiogenic pulmonary edema, usually presenting with cough or dyspnea. There are a few reported cases in the literature of children developing HAPE after ascending from an altitude of 1524 to $3048 \mathrm{~m}$. Nearly all of those children developing HAPE with minimal altitude changes are found to have pulmonary hypertension or cardiac abnormalities. ${ }^{3}$ We report a novel case that describes a healthy child, with multiple prior episodes of ascent to the same altitude, suddenly developing HAPE without obvious provocation. The patient had been to this exact altitude two weeks previously without any symptomatology. The study participant's mother has given consent to participate and publish the report. Approval was also obtained from the CommonSpirit Health Research Institute, Englewood, $\mathrm{CO}$ institutional review board. 


\section{Case Report}

The patient was an 11-year-old male and an Aurora, Colorado (a Denver suburb) native. The patient was in his usual state of good health before making one of his customary trips (most recently two weeks prior) to an elevation of $2926 \mathrm{~m}$ to Breckenridge, $\mathrm{CO}$ in late February. Patient arrived in the evening and was sedentary throughout the night. Within hours of arriving, he started to develop a headache with associated nausea. Over the next twenty-four hours he developed a productive cough with foamy sputum and dyspnea. He had one episode of diarrhea and was more fatigued. In the morning, he was too dyspneic to engage in normal activities and was brought to the clinic by his father. His initial oxygen saturation was noted to be $86 \%$ on room air and he had a respiratory rate of 18 with a heart rate of 104 beats per minute. He was normotensive and afebrile. The physical exam revealed low-grade tachycardia, and distinct right-sided rales with minimal rales on the left. A twoview chest X-ray revealed diffuse patchy alveolar opacities on the right with a normal cardiac silhouette (see Figure 1). The differential diagnosis at this point induced pneumonia, upper respiratory tract infection, bronchitis, foreign body aspiration and asthma. In this resource limited environment, advanced imaging and laboratory testing was limited. The patient was placed on high-flow face mask oxygen and given oral dexamethasone. After two hours the patient was asymptomatic but required 2 liters of nasal cannula oxygen to maintain his saturation in the

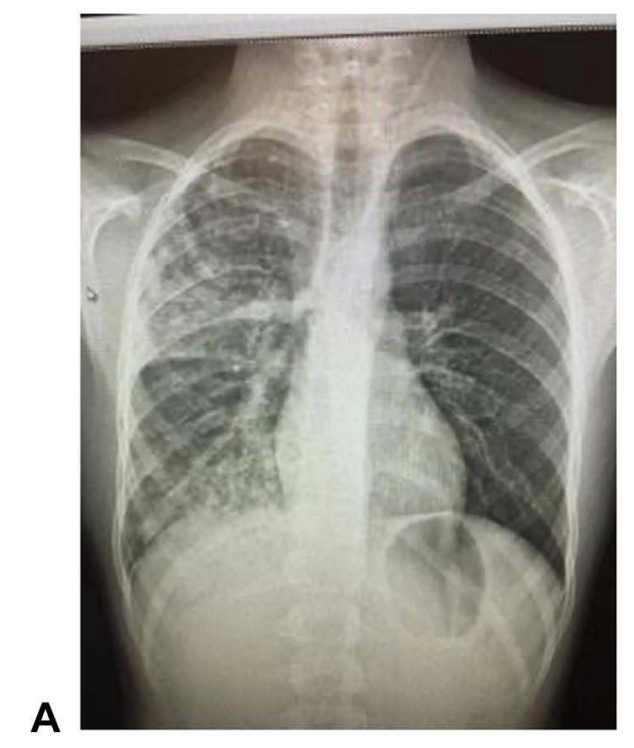

mid-90s. He was instructed to descend and was discharged on oxygen. He was symptom free later that evening on room air, after returning to his native altitude of $1578 \mathrm{~m}$. He was evaluated by his primary care physician the following day and his examination was unremarkable with normal oximetry. He was subsequently evaluated by a pediatric pulmonologist and an echocardiogram was performed. The echocardiogram was normal. Specifically, there was no structural abnormality and revealed no signs of pulmonary hypertension. A few weeks later the patient was able to return to the mountains to a maximum altitude of $3961 \mathrm{~m}$ and had no recurrence of pulmonary edema.

\section{Discussion}

HAPE is a rare, but potentially fatal occurrence in children. This is exceedingly rare in an otherwise healthy child ascending only $1348 \mathrm{~m}$ above their native altitude. Literature throughout the years has demonstrated risk factors for children that develop HAPE. These include children with recent acute viral illness, those that live at high altitudes and descend to a lower altitude for a period of weeks prior to returning home without acclimatization (reentry HAPE), or those with cardiopulmonary abnormalities. $^{4-6}$ Although there are different etiologies for HAPE, there is a suspected common pathophysiological pathway. When an individual ascends to a higher altitude the partial pressure of oxygen decreases. This decrease in the partial pressure of oxygen in the air will decrease the partial pressure of arterial oxygen $(\mathrm{PaO} 2)$. As

B

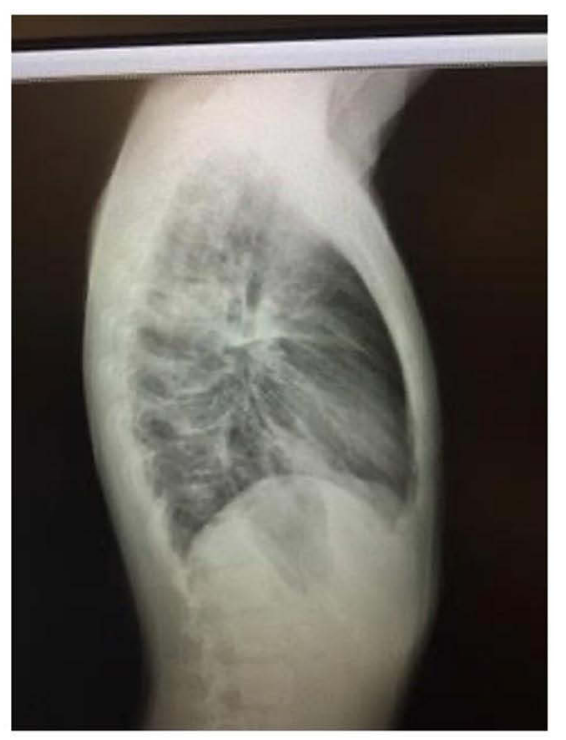

Figure I The PA (A) and lateral (B) views of the chest X-ray obtained during visit. 
the patient becomes hypoxemic from decreased $\mathrm{PaO} 2$, the pulmonary vasculature responds by vasoconstricting to maximize oxygen binding during the diffusion process. When excessive pulmonary vasoconstriction occurs, pulmonary hypertension ensues and there is hydrostatic flow across the pulmonary vasculature into the terminal bronchioles and alveoli resulting in pulmonary edema and alveolar infiltrates without cardiomegaly ${ }^{7}$ This is caused by sympathetic overactivation, defective nitric oxide production and exaggerated endothelin 1 synthesis. In addition, hypoxia may cause increased vascular endothelial growth factor production that leads to increased pulmonary vascular permeability and exudation of a protein and erythrocyte-rich fluid into the alveoli. Finally, hypoxia reduces fluid clearance from the alveolar space by inhibiting membrane sodium potassium ATPase activity decreasing transepithelial sodium and water transport out of the alveolar space. $^{8}$

This case illustrates findings consistent with HAPE in a pediatric patient. The patient had dyspnea at rest, cough and rales that developed 24 hours after ascending from his native altitude. His presentation met the Lake Louise diagnostic criteria for HAPE. ${ }^{9}$ The patient was already living at a relatively high altitude and had previously been exposed to an altitude of $2926 \mathrm{~m}$ and higher multiple times. This does not fit the typical presentations of HAPE, especially in a healthy pediatric patient without any prior congenital heart abnormalities or recent illness.

This case illustrates the importance of awareness of altitude illness for clinicians as well the parents. For the clinician, diagnosing and treating this fatal illness in a timely manner is key. Misdiagnosis of HAPE as pneumonia is a common cause of morbidity and mortality. Diagnosis of HAPE can be difficult in pediatric patients, especially those that have been asymptomatically exposed to higher altitudes in the past. The treatment for HAPE is primarily to reverse the underlying cause by increasing the $\mathrm{PaO} 2$ to decrease pulmonary vasoconstriction. In this case, high-flow face mask oxygen was utilized, in addition to the definitive treatment, which is descent to a lower altitude. ${ }^{10}$ Prevention and treatment of HAPE with acetazolamide, sildenafil and nifedipine have been found to be efficacious. Dexamethasone has been used in the treatment of AMS and High Altitude Cerebral Edema. There is evidence for starting dexamethasone for those presenting with HAPE symptoms. ${ }^{11}$ Noninvasive positive pressure ventilation has limited evidence of efficacy but may be difficult to use in the pediatric population due to mask- induced agitation. ${ }^{12}$ Prophylaxis was not recommended for this patient upon return to altitude based on his multiple prior asymptomatic ascents. Careful observation of the patient was recommended without pharmacologic treatment. From the parent perspective it is vital to recognize dyspnea-related symptoms due to altitude before it progresses to a life-threatening stage of pulmonary edema. Gradual ascent remains the most effective means of acclimatization.

\section{Disclosure}

The authors report no conflicts of interest in this work.

\section{References}

1. Honigman B, Theis MK, Koziol-McLain J, et al. Acute mountain sickness in a general tourist population at moderate altitudes [published correction appears in Ann Intern Med 1994 Apr 15;120(8):698]. Ann Intern Med. 1993;118(8):587-592. doi:10. 7326/0003-4819-118-8-199304150-00003

2. Sophocles AM Jr. High-altitude pulmonary edema in Vail, Colorado, 1975-1982. West J Med. 1986;144(5):569-573.

3. Giesenhagen AM, Ivy DD, Brinton JT, Meier MR, Weinman JP, Liptzin DR. High altitude pulmonary edema in children: a single referral center evaluation. $J$ Pediatr. 2019;210:106-111. doi:10. 1016/j.jpeds.2019.02.028

4. Durmowicz AG, Noordeweir E, Nicholas R, Reeves JT. Inflammatory processes may predispose children to high-altitude pulmonary edema. J Pediatr. 1997;130(5):838-840. doi:10.1016/ s0022-3476(97)80033-9

5. Scoggin CH, Hyers TM, Reeves JT, Grover RF. High-altitude pulmonary edema in the children and young adults of Leadville, Colorado. N Engl J Med. 1977;297(23):1269-1272. doi:10.1056/ NEJM197712082972309

6. Das BB, Wolfe RR, Chan KC, Larsen GL, Reeves JT, Ivy D. Highaltitude pulmonary edema in children with underlying cardiopulmonary disorders and pulmonary hypertension living at altitude. Arch Pediatr Adolesc Med. 2004;158(12):1170-1176. doi:10.1001/ archpedi.158.12.1170

7. Stream JO, Grissom CK. Update on high-altitude pulmonary edema: pathogenesis, prevention, and treatment. Wilderness Environ Med. 2008;19(4):293-303. PMID: 19099331. doi:10.1580/07-WEMEREV-173.1

8. Li Y, Zhang Y, Zhang Y. Research advances in pathogenesis and prophylactic measures of acute high altitude illness. Respir Med. 2018;145:145-152. PMID: 30509704. doi:10.1016/j.rmed.2018. 11.004

9. Roach RC, Hackett PH, Oelz O, et al. The 2018 Lake Louise Acute Mountain Sickness Score. High Alt Med Biol. 2018;19(1):4-6. doi:10.1089/ham.2017.0164

10. Davis C, Hackett P. Advances in the prevention and treatment of high altitude illness. Emerg Med Clin North Am. 2017;35(2):241-260. doi:10.1016/j.emc.2017.01.002

11. Luks AM, MacIntosh SE, Grissom CK, et al. Wilderness Medical Society consensus guidelines for the prevention and treatment of acute altitude illness: 2019 Update. Wilderness Environ Med. 2019;30(4S):S3-S18. doi:10.1016/j.wem.2019.04.006

12. Johnson PL, Johnson CC, Poudyal P, Regmi N, Walmsley MA, Basnyat B. Continuous positive airway pressure treatment for acute mountain sickness at $4240 \mathrm{~m}$ in the Nepal Himalaya. High Alt Med Biol. 2013;14(3):230-233. doi:10.1089/ham.2013.1015 


\section{Publish your work in this journal}

The Open Access Emergency Medicine is an international, peerreviewed, open access journal publishing original research, reports, editorials, reviews and commentaries on all aspects of emergency medicine. The manuscript management system is completely online

Submit your manuscript here: https://www.dovepress.com/open-access-emergency-medicine-journa and includes a very quick and fair peer-review system, which is all easy to use. Visit http://www.dovepress.com/testimonials.php to read real quotes from published authors. 